\title{
Sand and dust storm events in Iraq
}

\author{
Varoujan K. Sissakian ${ }^{1}$, Nadhir Al-Ansari ${ }^{2 *}$, Sven Knutsson ${ }^{2}$ \\ ${ }^{1}$ Consultant Geologist, Erbil, Iraq; varoujan49@yahoo.com \\ ${ }^{2}$ Luleå University of Technology, Luleå, Sweden; ${ }^{*}$ Corresponding Author: nadhir.alansari@ltu.se, $\underline{\text { Sven.Knutsson@ltu.se }}$
}

Received 31 August 2013; revised 30 September 2013; accepted 7 October 2013

Copyright (C) 2013 Varoujan K. Sissakian et al. This is an open access article distributed under the Creative Commons Attribution License, which permits unrestricted use, distribution, and reproduction in any medium, provided the original work is properly cited.

\begin{abstract}
Iraq is one of the most affected countries in the Middle East concerning the occurrences of sand and dust storms. The frequency of the occurrence has increased drastically in the last decade and it is increasing continuously. The events of sand and dust storms are either regional or local. The former, however, is more frequent than the latter. The regional event, generally extends outside the Iraqi territory, into different directions, but usually covers part of Syria, crossing the Iraqi territory towards Kuwait and Saudi Arabia, and/or towards the Arabian Gulf, and less frequently extends to Iran. The main causes in the development of sand and dust storms, in Iraq are discussed. The causes are also either regional or local. The former, however, causes more economic losses and harsh effect on the human's health, as compared with the latter. One of the main reasons behind the development of sand and dust storms is the climatic changes within the region, especially the drastic decrease in the annual rate of rain fall, besides environmental changes, such as drying of the marshes, land degradation, and desertification. From the local causes, the most effective reason is the haphazard driving and military operations, especially in the Iraqi Southern Desert. Prudent management of water resources by using non-conventional resources and adapting suitable irrigation methods can greatly help to overcome this phenomenon and minimize the number of dust storm.
\end{abstract}

Keywords: Dust; Dust Storm; Climatic Changes; Iraq

\section{INTRODUCTION}

Some countries are geographically situated in a posi- tion that sand and dust storms (SDS) often stuck with them. Unfortunately, Iraq is one of those countries where dust storms hit and last for days. Iraq's summertime climate is hot, dry, and dusty. Dust storms are driven by a northwest wind called the "Shimali" (means in Arabic language; from the north) that can rip through the Tigris and Euphrates River valleys of central and southern Iraqat any time of the year, and blow almost constantly through June and July (Figure 1). However, in August and September it might still blow. Shimali winds can last for several days in a row, strengthening during the day and weakening at night, and creating devastating dust storms.

The Ministry of Environment, in Iraq recorded 122 dust storms and 283 dusty days, and sources suggest that within the next ten years Iraq could witness 300 dusty days and dust storms per year [1].

The aim of this study is to discuss the types of sand and dust storms in Iraq, their regional and local exten-

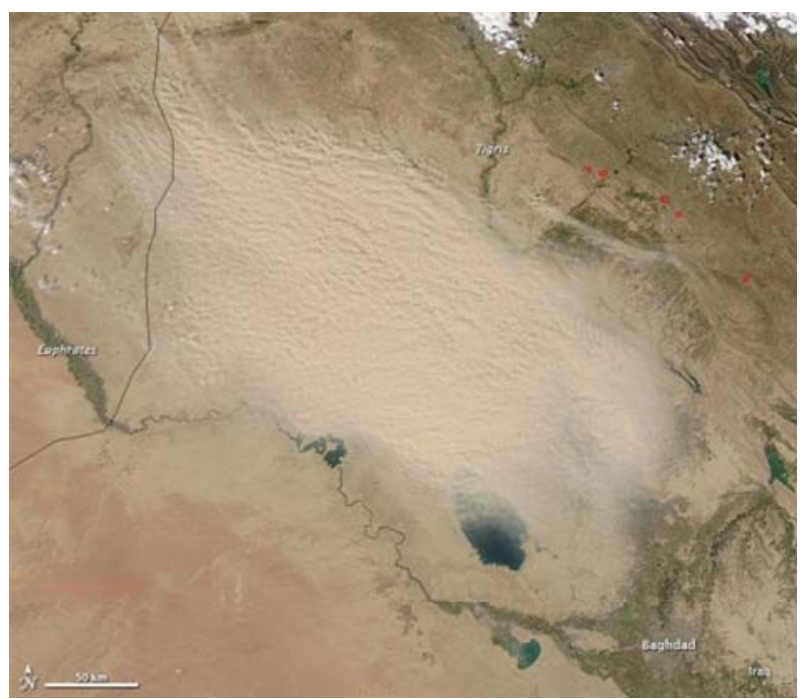

Figure 1. Aerial view of a dust storm. Note it had started just in the northwestern borders of Iraq (The Moderate Resolution Imaging Spectroradiometer (MODIS) on NASA's Aqua satellite captured this natural color image on March 3, 2011). 
sions, also to discuss the causes of the development of dusts and dust storms. Moreover, to present their economic and social impacts, by mentioning many events, some of them are historical.

This study was performed depending on the available Internet data, concerning the dealt subject. Tens of concerned articles were reviewed; some historical books and newspapers were reviewed too. The acquired data are used in writing of this article.

\section{SAND AND DUST STORMS}

Iraq is considered as one of the region's most vulnerable countries to climate changes, and it faces a unique set of environmental degradation and increasing frequency and intensity of extreme weather events, especially sand and dust storms (SDS). This takes an enormous toll on socio-economic life and human development in the region. Iraq is affected by the southern and southeasterly wind called "Shargi" (in Arabic language means from the south), which is a dry wind with occasional gusts of 80 $\mathrm{Km} / \mathrm{hr}$, occurs from April to early June and again from late September through November. This wind brings with it violent dust storms that may rise to heights of several thousand meters. From mid-June to mid-September, the "Shiamli" wind blows from the north and northwest. The very dry air permits intensive heating and aggravates desertification. It is particularly these two winds, which generate severe SDS in the region [2].

A sand and/or dust storm (sand storm) is a meteorological phenomenon common in arid and semi-arid regions. Dust storms arise when a gust front or other strong wind blows loose sand and dirt from a dry surface. Particles are transported by saltation and suspension, a process that moves soil from one place and deposits it in another [3]. The term sand storm is used most often in the context of desert sandstorms, especially in the deserts, or places where sand is a more prevalent soil type than dirt or rock, when, in addition to fine particles obscuring visibility, a considerable amount of larger sand particles are blown closer to the surface. The term dust storm is more likely to be used when finer particles are blown long distances, especially when the dust storm affects urban areas.

\subsection{Development of SDS}

In addition to its arid climate (i.e., extreme heat, low humidity and little precipitation) the most notable natural hazard in Iraq (and surrounding areas) are dust and sand storms. These storms are generally prevalent in the spring and summer when a prevailing northwesterly wind ("Shimali") kicks up the fine desert sand and the silt along the Tigris and Euphrates river basins [4]. Sissakian et al. [5] also considered the sand dunes, which are one of the sources of dust and dust storms, as one on the main geological hazards in Iraq.

Sand and Dust Storms are usually developed in arid and semi-arid regions. They may extend covering very large area, hence are considered as regional, or have limited extensions and considered as local. In both cases, their development is described as "The initial saltation of sand particles induces a static electric field by friction. Saltating sand acquires a negative charge relative to the ground, which in turn loosens more sand particles which then begin saltating. This process has been found to double the number of particles predicted by previous theories" [6]. Particles become loosely held mainly due to drought or arid conditions, and varied wind causes. Gust fronts might be produced by the outflow of rain-cooled air from an intense thunderstorm, or it might be produced by a dry cold front moving into a dry air mass and is producing no precipitation.

In desert areas, SDS events are most commonly caused by either thunderstorm outflows, or by strong pressure gradients, which cause an increase in wind velocity over a wide area. The vertical extent of the dust or sand that is raised is largely determined by the stability of the atmosphere near the ground; as well as by the weight of the particulates. In some cases, dust and sand may be confined to a relatively shallow layer by a low lying temperature inversion. In other instances, dust may be lifted as high as $6100 \mathrm{~m}$ high [2].

Dust and sand storms are a persistent problem in Iraq and other areas in the Middle East, but they are most prevalent during the spring and summer months due to the strong winds that characterize the weather during the winter-spring seasonal transition. Specifically, dust and sand storms occur when the strong (mostly dry) storms (that often accompany well-defined cold fronts) stir up these particles. Dust and sand lift both ahead of and (even more so) behind cold fronts (since winds tend to be stronger behind the front than ahead of it). This seasonal trend can best be characterized as a combination of two separate weather systems: the sub-tropical jet stream pushing up from south of the Arabian Peninsula and a polar front jet stream pushing down from the European continent. When these two systems come within close proximity, they create much more dynamic weather than is usually found within this region, especially the strong northwesterly "Shimali" winds [7].

The larger the particles, the stronger the wind required to lift them into the air. But, for there to be any longrange transport, there also needs to be considerable vertical motion. The vertical speed determines how much the particulate matter is lifted through the air. Another factor that influences the impact of the "Shimali" is the dampness of the sand. Even a very small amount of precipitation can keep a tremendous amount of sand from 
entering the air.

The unique topography and human intervention within the region also contribute to the frequency and intensity of dust and sand storms in this area. The natural funneling of large air masses by the high mountains in Turkey and Iran combined with the high plateaus in Saudi Arabia, help to funnel air across the Mediterranean into the Persian Gulf. Furthermore, many Iraqi wetlands have been drained for agriculture or seriously deprived of water by reservoirs upstream. This exacerbates dust as wind lifts dry silt from exposed lake and marsh beds.

Depending on location, it is not unusual for Iraq to encounter (20 - 50) days of blowing sand and dust each year. Dust can persist for days; however, because the air is so dry, there are wide diurnal temperature differences that can influence dust and sand storms (especially during the summer months). In other words, rapid heat loss at night lowers the temperature inversion, helping to settle the dust and sand. Therefore, dust and sand storms generally subside at the source soon after sunset and are strongest in the late morning and afternoons.

Usually, the fronts of dust storms are accompanied with strong wind, and occasionally rain drops, which may last for few minutes. The height of the front never exceeds $25 \mathrm{~m}$, usually ranges between (10 - 15) m [2] (Figure 2), and it has two sharp lateral boundaries (Figure 3), this is attributed to the difference in the pressure. In dusts, however, neither front nor sharp lateral boundaries exist. Moreover, the height of the sand (dust) is much higher than the dust storm, and the settling time in the former is much longer than the latter. This is attributed to the strong wind (up to $120 \mathrm{Km} / \mathrm{hr}$ ) that accompanies the latter, which blows the sand and/or the dust far away to be settled.

Technically speaking there are subtle, yet distinct differences between dust and sand storms [7]. The main differences between them are mentioned hereinafter.

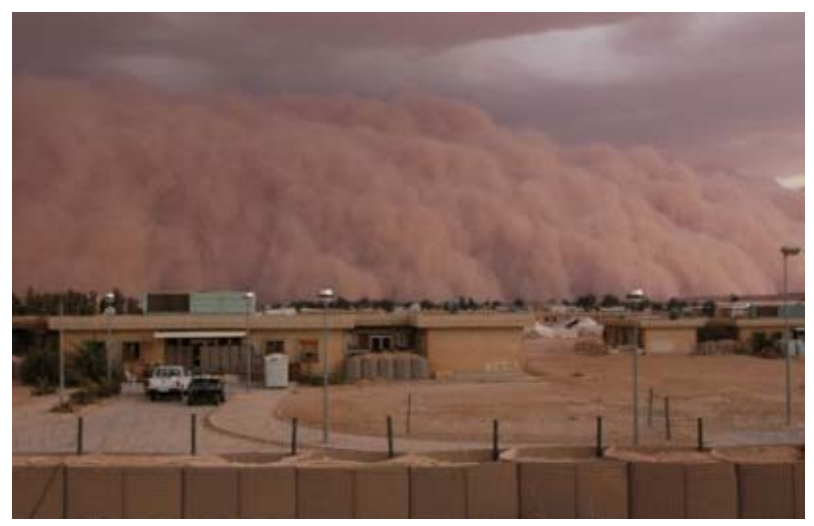

Figure 2. Dust storm in the Iraqi Western Desert, west of Falluja. Compare the height of the front with the heights of the buildings, and note the clouds, which accompanied the dust storm.

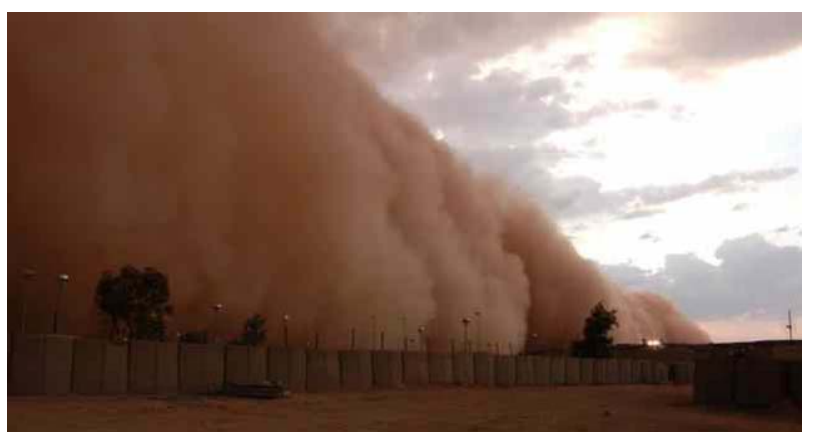

Figure 3. Dust storm in the Iraqi Western Desert Note its sharp right-hand boundary.

\subsection{Sad Storm}

Is basically a wind storm that carries sand through the air, forming a relatively low cloud near the ground. Typical sandstorms only reach heights of up to $15 \mathrm{~m}$, contain sand particles with average sizes between $(0.15-0.30)$ $\mathrm{mm}$, have wind speeds exceeding $14 \mathrm{Km} / \mathrm{hr}$ and last as long as wind speeds persist. When wind reaches a critical velocity, grains of sand begin to roll forward along the ground surface. For higher wind speeds, sand particles in a sand storm move by "saltation". When one saltating grain collides with another, the impact may lift either particle into the air. Once aloft, these particles are subjected to the forces of gravity (pulling them down) and horizontal wind velocity... and the process starts all over again. Once a dust storm starts, it roughly increases as the cube of the wind speed, as it is illustrated in Figure 4.

A Dust Storm is a similar phenomenon, but has distinctly different characteristics. Dust storms form in semi-arid and arid regions where small dust (and sand) particles are literally blown through the air. Unlike in pure sand storms, dust particles are small enough to be lifted aloft by currents of turbulent air and carried into suspension. Ironically, however, research has shown that wind does not usually pick up dust-sized particles less than $0.05 \mathrm{~mm}$ in diameter along many completely smooth surfaces because each individual dust particle either: 1) lies within a zone of air that is protected by larger particles or aggregates (right along the surface of the desert) or 2) is aggregated onto the surface of a larger particle or larger aggregate. Under these circumstances, sufficient energy to liberate the small particles from the surface is delivered by saltating sand-sized particles. Irregularities in the surface or the presence of sand grains may create sufficient turbulence, so that sand grains gain sufficient wind energy to initiate saltation. Saltation-free dust emissions are possible, but rare, found in fine material where sand grains or sand-sized aggregates are not found. Vertical downdrafts of chilled air during thunderstorms may locally strike the ground with velocities of $(40-80) \mathrm{km} / \mathrm{hr}$. 


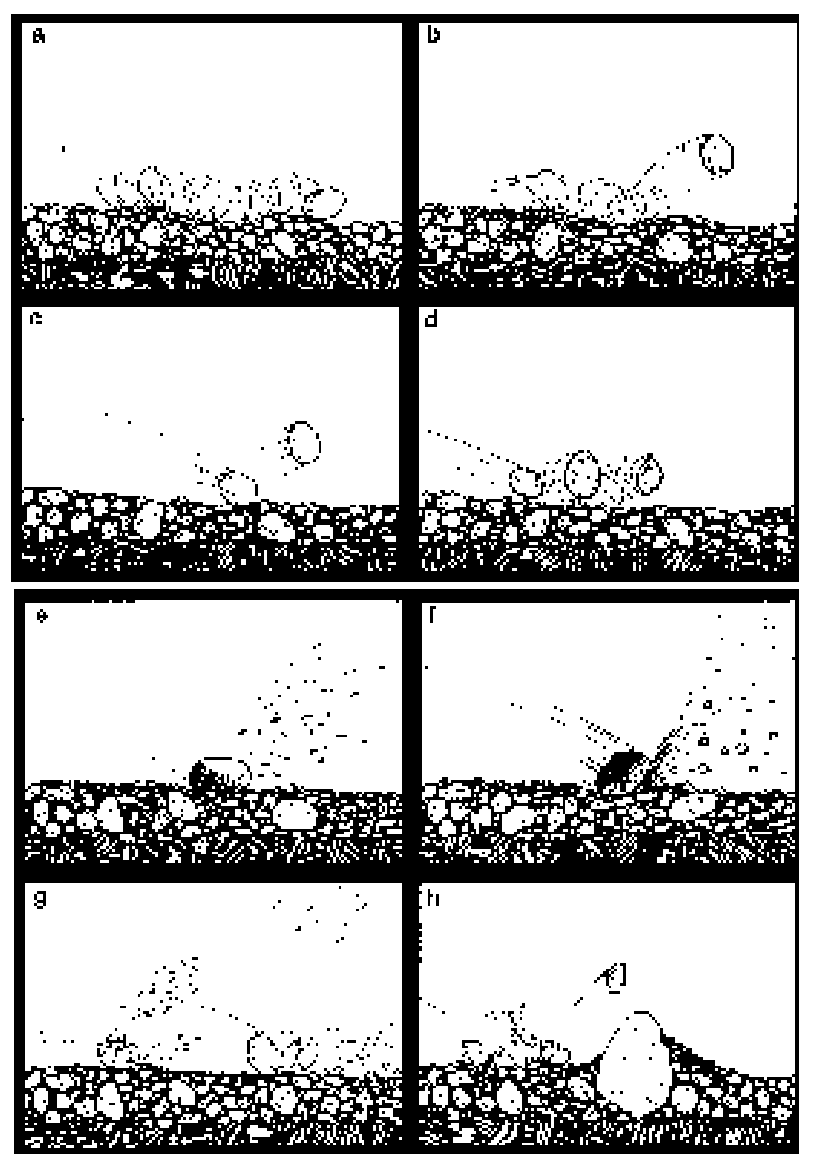

Figure 4. Eight steps (from a to h) illustrating the development of a dust storm [8].

Under such conditions, fine particles may also be swept upwards hundreds or thousands of feet into the air. The average height of a dust storm is (1000 - 2000) $\mathrm{m}$ and stronger storms have dust to $(2750-3500) \mathrm{m}$. Haze and dust with extreme storms have been documented as high as $(10,000-12,500)[7]$.

\section{Causes of Dust and Dust Storms (SDS)}

The main cause for developing a dust storm is given by [3] "As the force of wind passing over loosely held particles increases, particles of sand first start to vibrate, then to saltate ('leap'). As they repeatedly strike the ground, they loosen and break off smaller particles of dust, which then begin to travel in suspension. At wind speeds above that, which causes the smallest to suspend, there will be a population of dust grains moving by a range of mechanisms: suspension, saltation and creep". However, SDS is the results of much inter dependent factors, which span across several regional countries. Years of inappropriate farming practice, mismanagement of water resources and climate change continue to contribute to reduced vegetation coverage, desertification and droughts, which direct- ly contribute to the growing regional SDS problem. Droughts and arid conditions favor the dissolution of soil particles, and wind contributes to the emergence of SDS.

\subsection{Regional SDS}

The regional SDS has a very wide extension; it may cover many countries (Figures 5-8). Iraq and neighboring countries have witnessed a large number of SDS, which is drastically increased in the last decade, and may reach to 300 events in the year $2013[9,10]$. The factors controlling development of local dust are described hereinafter.

\subsection{Draught, Water Deficiency and Marshes}

Since the last decade, the annual rain fall has drasticcally decreased causing draught; not in Iraq but in all surrounding areas (countries). The annual rainfall, annual precipitation and annual dust storms; for the duration 1951-1990 in different parts of Iraq is mentioned in Table 1, whereas the annual rainfall throughout the year 2012 was between $(100-200) \mathrm{mm}$ and $(200-400) \mathrm{mm}$; in the southern lower part and northern upper part of Iraq,

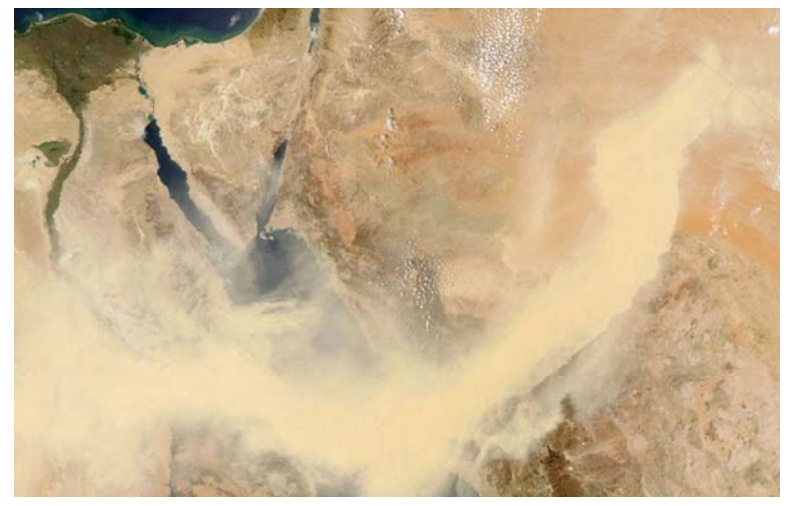

Figure 5. A dust storm crossing the Red Sea from Egypt to Saudi Arabia, on May 13, 2005 (Courtesy of Aqua).

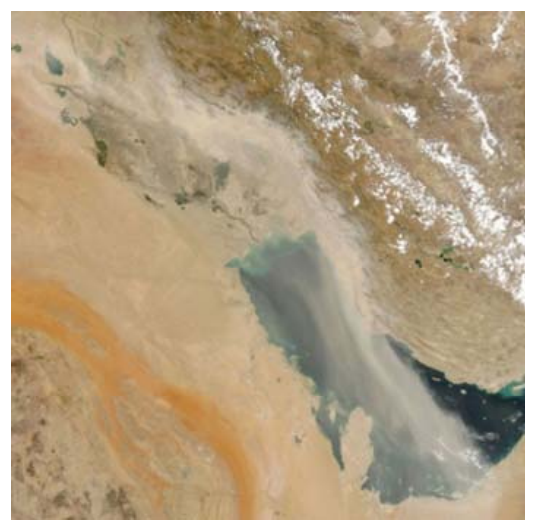

Figure 6. A dust storm hitting Kuwait, south of Iraq, and the Arabian Gulf, on August, 9, 2005 (Courtesy of Aqua). 


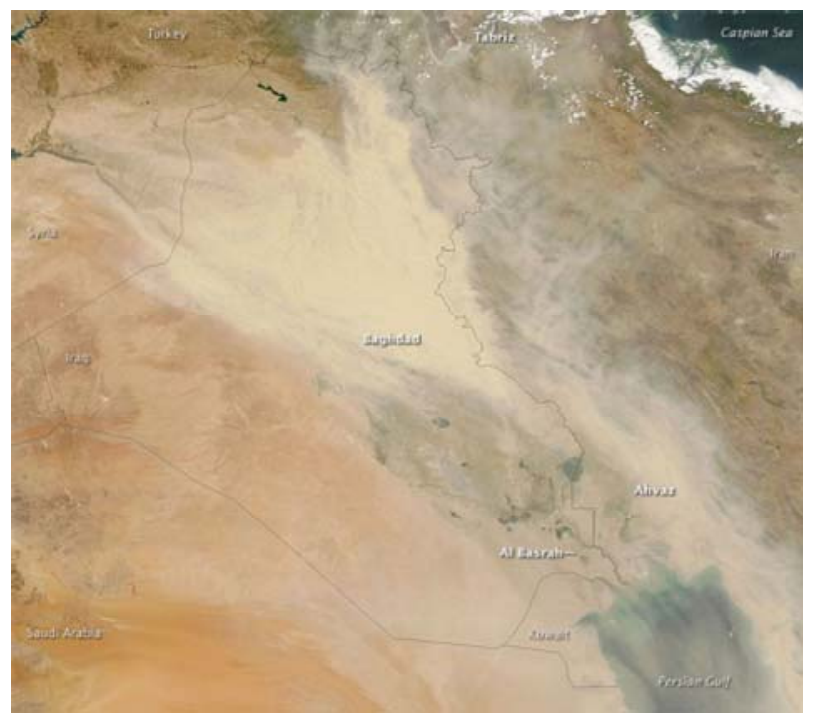

Figure 7. A regional dust storm hitting Iraq, parts of Iran, Saudi Arabia, Kuwait and the Arabian Gulf.

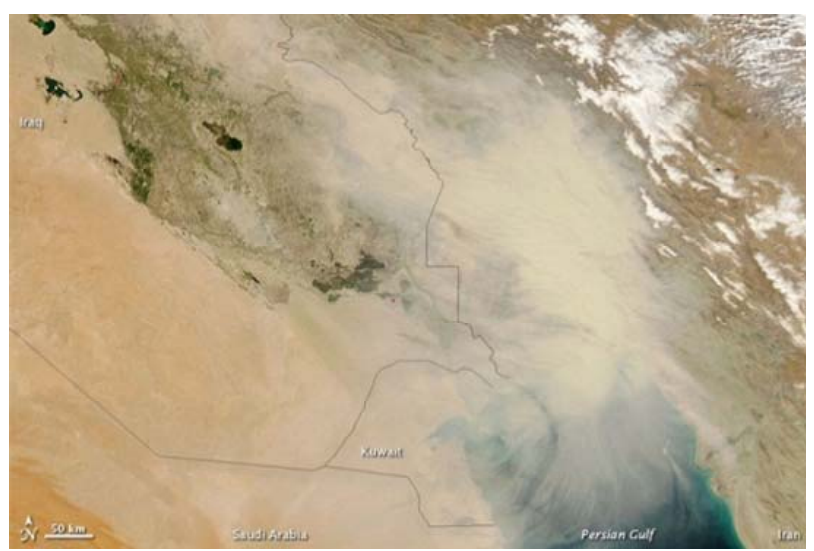

Figure 8. Dust storm hitting southeast of Iraq, Kuwait, part of Iran and the Arabian Gulf (Courtesy of Aqua).

respectively [11]. Due to this decrease in the annual rainfall, the ground surface has lost its vegetation cover, which was lasting for few months; usually starting from January or February to the end of May. The removal of the vegetation cover contributed in the loosening of the top soil cover, consequently leading toward the development of particles of clay and sand size. These particles were in action during windblown; causing development of sand storms and dust; as elucidated in Figure 4.

Another reason for water deficiency and draught is the construction of dams in Turkey, Iran and Syria, which have decreased the annual water flow in the Tigris and Euphrates Rivers, and their tributaries $[11,12]$. In addition, drying the marshes prior 2003 and the obstacles encountered in restoring them is another factor contributing to the generation of these storms [13]. This had led to enormous decrease in the agricultural lands (Figure 9), which intern have changed to dry lands and have con-
Table 1. Climatic data ${ }^{*}$ (after Iraqi Meteorological Organization).

\begin{tabular}{ccccc}
\hline Governorate & $\begin{array}{c}\text { Mean annual } \\
\text { rainfall }(\mathrm{mm})\end{array}$ & $\begin{array}{c}\text { Mean annual } \\
\text { temperature } \\
\left({ }^{\circ} \mathrm{C}\right)\end{array}$ & $\begin{array}{c}\text { Mean annual } \\
\text { dust storms } \\
\text { (days) }\end{array}$ & $\begin{array}{c}\text { Dryness } \\
\text { index }\end{array}$ \\
\hline Baghdad & $150-200$ & 23 & 12 & $20-25$ \\
Mosul & $300-600$ & $18-20$ & $1-4$ & $5-10$ \\
Basra & $75-150$ & 24 & $8-24$ & $15-20$ \\
Erbil & $400->800$ & $<16-19$ & $1-4$ & $<5$ \\
Suliamaniyah & $500->800$ & $<16-18$ & $1-2$ & $<5$ \\
Dohuk & $600->800$ & 18 & 1 & $<5$ \\
Kirkuk & $200-400$ & $20-22$ & $2-4$ & $5-10$ \\
Salah Al-Deen & $100-300$ & $22-23$ & $4-12$ & $10-20$ \\
Diyala & $150-450$ & 23 & $4-12$ & $15-20$ \\
Anbar & $<75-150$ & $18-22$ & $4-8$ & $20-35$ \\
Wasit & $150-200$ & 23 & $2-6$ & $20-25$ \\
Misan & $150-200$ & 23 & $2-8$ & $15-25$ \\
Babil & $100-150$ & 23 & $10-12$ & $25-30$ \\
Karbala & $75-100$ & $22-24$ & $8-12$ & $30-35$ \\
Najaf & $75-100$ & $22-24$ & $8-12$ & $30-35$ \\
DhiQar & $100-150$ & 24 & $6-12$ & $20-30$ \\
Qadisiyah & $100-150$ & $23-24$ & $6-24$ & $25-30$ \\
Al-Muthan'na & $<75-100$ & 24 & $12-24$ & $25-35$ \\
\hline
\end{tabular}

*Climatic Atlas of Iraq (1951-1990).

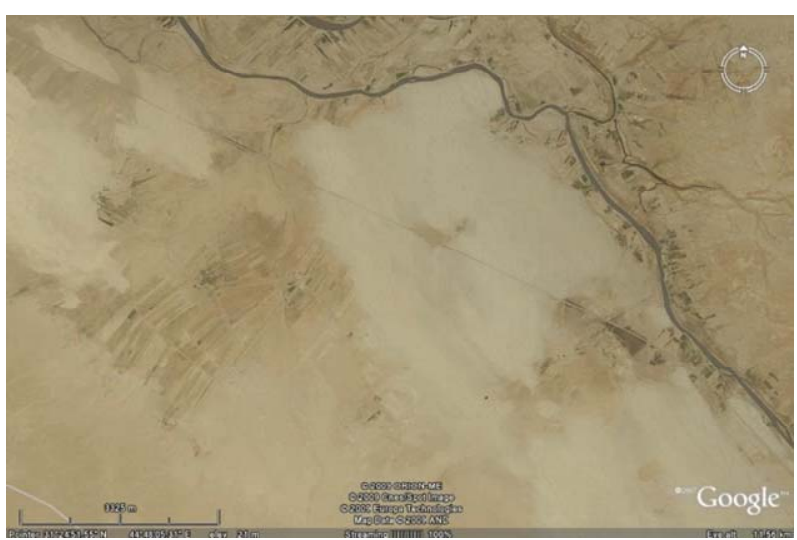

Figure 9. Creeping of sand dunes over agricultural lands; south and south west of Samawa city. Note that some of the ploughed lands still can be seen in between the sand.

tributed in desertification, consequently increasing SDS events, due to disintegration of the soil particles and wind contributes to the emergence of SDS. Therefore, the majority of the Iraqi territory is changed into Very High Potential for dust storm areas, except small part in 
the extreme northeastern part, where it shows Moderate Potential for dust storms, as it is shown in Figure 10.

\subsection{Climatic Changes}

There are enormous changes of different climatic factors in Middle East due to global climate change; since the last decade. Global climate change and GAP project in Turkey are both contributing to the water shortages in Iraq [11-13,15-23]. The area experienced enormous changes in annual average temperature, and rain fall had occurred and as a result number of annual dust storms was witnessed in Iraq. There are growing concern that most of the agricultural land in Iraq will be converted to desertic areas [11-13,15-23] (Figure 11). All these factors contribute to the increase in dust storms. The maximum number of annual dust storms during 1951-1990 was about 24 days/year (Table 1), whereas the predicted number of annual dust storms during 2013 is estimated to be 300 days [1]. Almost all parts of Iraq; exhibit extreme dust storms, which may last for few days (Figure 12).

\subsection{Local SDS}

The local dust does not extend for long distances, because the causes of the emission have not enough energy to carry the dust for long distances. The factors controlling development of local dust are described hereinafter.

\subsection{Agricultural Operations}

Local dust emissions from agricultural operations result from the disturbance of soil inherent in the preparation of agricultural lands for planting and after harvest activities. These operations generate enormous quantities of sediment ready to be transported by air or water [24, 25]. These include dicing, leveling, and other mechanical operations. Dust emissions from this category exhibit a seasonal pattern as planting and harvesting generally occur during the spring and fall, respectively. In addition,

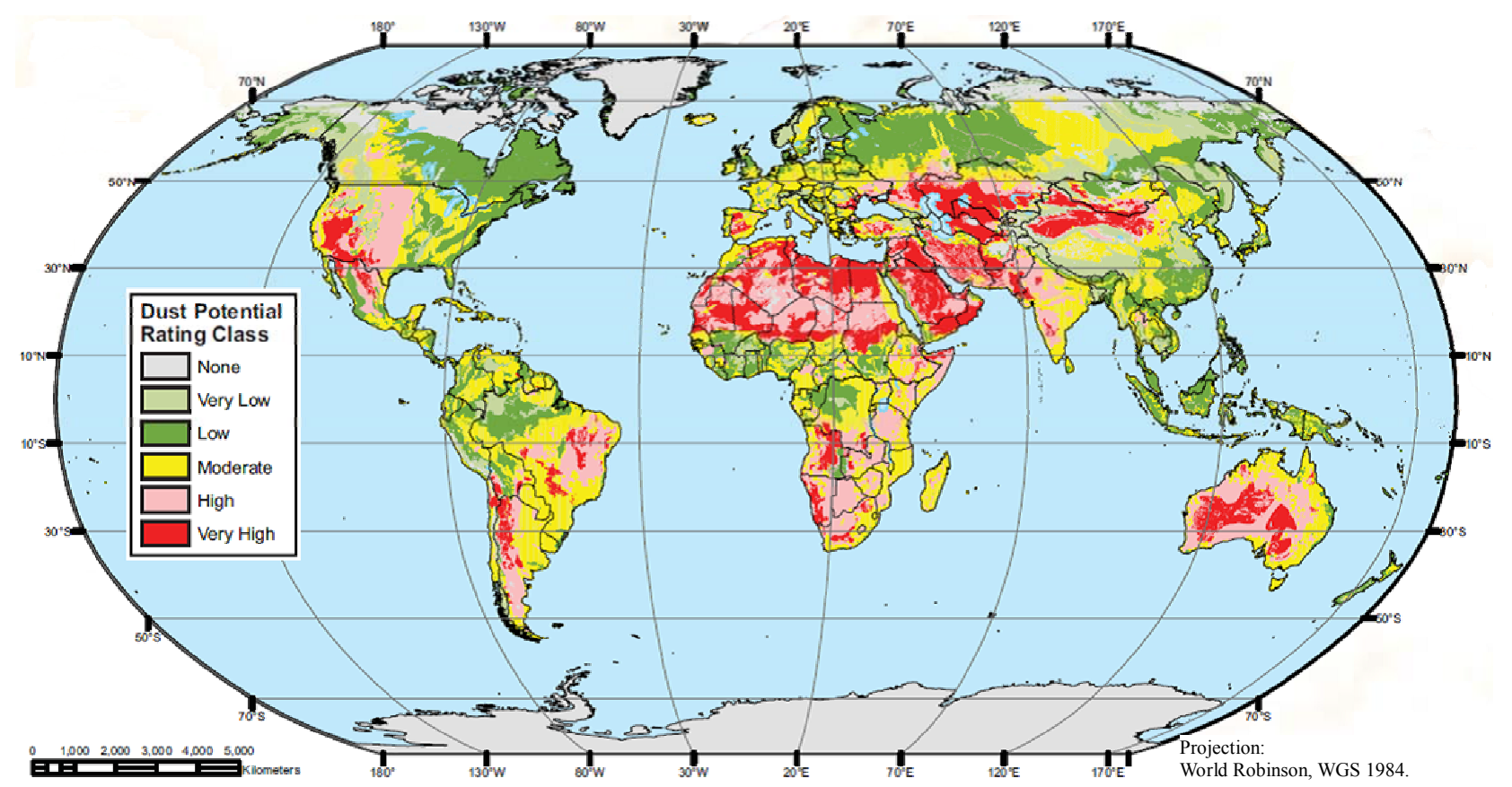

Figure 10. Global Dust Potential Map (After DTF, 2013).

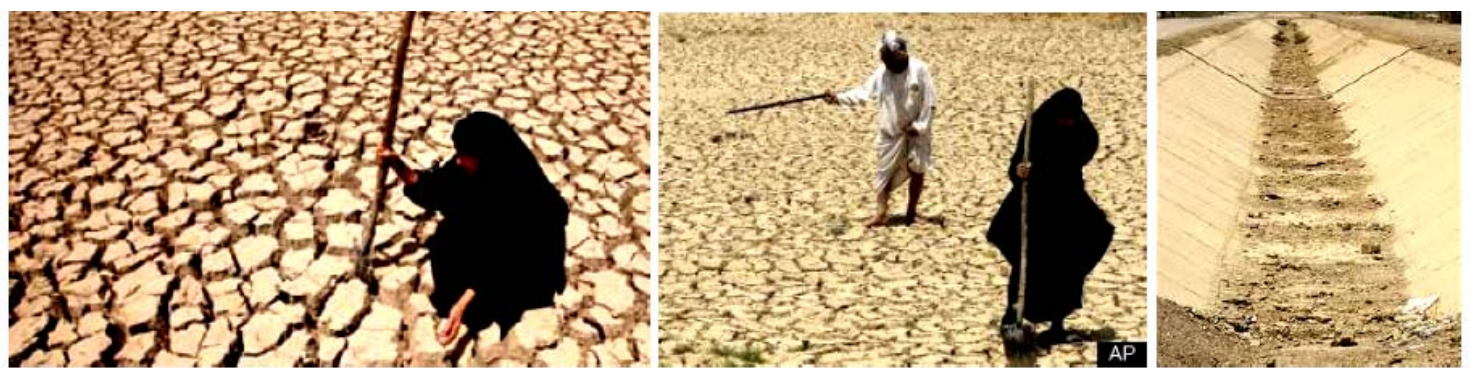

Figure 11. Water shortage and climate change converted agricultural lands converted to desertic areas in Iraq. http://www.nbcnews.com/id/31890377/ns/weather/t/iraq-drought-continues-sandstorms-worsen/ 


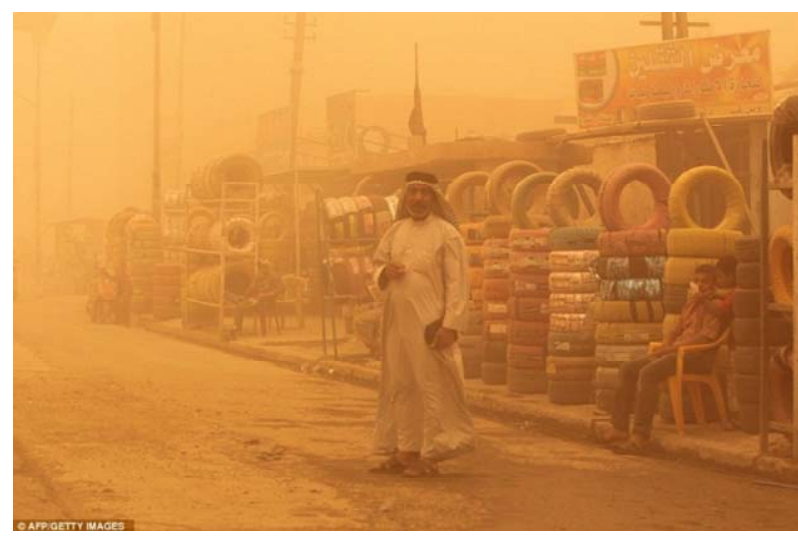

Figure 12. Heavy dust storm in Baghdad, a local market (2012).

agricultural practices and planting and harvesting calendars are crop-specific in many cases. Besides, to operations associated with agricultural land preparation and harvesting, this emission source category includes dust emissions arising from the transport of agricultural crops as well as dust from agricultural feedlots or confined animal feeding operations.

\subsection{Construction Operations}

Construction operations are a significant source of local dust emissions that may have a substantial temporary impact on local air quality [25]. This emission source category includes both residential and non-residential construction as well as road construction. Dust emissions during the construction of buildings or roads are associated with land clearing, drilling and blasting, ground excavation, and cut and fill operations (i.e., earth moving). Local dust emissions can vary substantially from day to day, depending on the level of activity, the specific operations, and the prevailing meteorological conditions. A significant amount of the local dust emissions resulted from construction vehicle traffic over temporary roads at construction sites. The two main types are mentioned hereinafter:

1) Residential Construction: Local dust emissions from residential construction are a function of the total acres of land disturbed and the volume of soil excavated. The volume of soil excavated also varies by type of structure under construction. County-level housing starts by structure type are used to estimate the disturbed acreage for construction.

2) Non-residential/Commercial Construction: Local dust emissions from non-residential and commercial construction are a function of the total acres of land disturbed.

\subsection{Road Construction}

Local dust emissions from road construction activities are a function of acres disturbed during construction.
These amounts of the emitted dust also vary by type of road. The length of a new constructed road is then used to estimate total acres disturbed using conversion factors for acres disturbed $/ \mathrm{Km}$ of road constructed, as a function of a road type.

\subsection{Paved Road Dust}

Particulate local emissions occur whenever vehicles travel over a paved surface, especially after dust storms and/or drying of the residual loamy cover; formed after rain showers. Particulate emissions from paved roads are due to direct emissions from vehicles in the form of exhaust, brake wear and tire wear emissions, and re-suspension of loose material on the road surface. Re-suspended particulate emissions from paved roads originate from, and result in the depletion of the loose material present at the surface (i.e., the surface loading at industrial sites), surface loading is replenished by spillage of material and track-out from unpaved roads and staging areas.

Local dust emissions from paved roads have been found to vary with the "silt loading" present on the road surface as well as the average weight of vehicles traveling the road. The term silt loading (sL) refers to the mass of silt-size material $(\leq 75 \mu \mathrm{m})$ per unit area on the travel surface. The total road surface dust loading consists of loose material that can be collected by broom sweeping and vacuuming of the traveled portion of the paved road.

The surface silt loading (sL) provides a means of characterizing seasonal variability in a paved road emission inventory. In many areas throughout the country, road surface silt loadings are heaviest during the late winter and early spring months when the residual loading from snow/ice controls is greatest. Once replenishment of fresh material is eliminated, the road surface silt loading can be expected to reach an equilibrium value, which is substantially lower than the late winter/early spring values.

Particulate emissions from road surfaces due to vehicle travel on a dry paved road may be estimated using the following empirical expression [8].

$$
E=k\left(\frac{s L}{2}\right)^{0.65} \times\left(\frac{W}{3}\right)^{1.5}-C
$$

where, $E=$ particulate emission factor (having units matching the units of $k), k=$ particle size multiplier for particle size range, $s L=$ road surface silt loading (grams per square meter, $\left.\mathrm{g} / \mathrm{m}^{2}\right), W=$ average weight (tons) of the vehicles traveling the road, and $C=$ emission factor for 1980's vehicle fleet exhaust, brake wear and tire wear.

\subsection{Unpaved Road Dust}

When a vehicle is traveling on an unpaved road then, the force of the wheels on the road surface causes pul- 
verization of surface material. Particles are lifted and dropped from the rolling wheels, and the road surface is exposed to strong air currents in turbulent shear with the surface. The turbulent wake behind the vehicle continues to act on the road surface after the vehicle has passed. The quantity of dust emissions from a given segment of unpaved road varies linearly with the volume of traffic [26]. Dust emissions also depend on source parameters that characterize the condition of a particular road and the associated vehicle traffic. Characterization of these source parameters allow for "correction" of emission estimates to specific road and traffic conditions present on public and industrial roadways.

Dust emissions from unpaved roads have been found to vary directly with the fraction of silt (particles smaller than $75 \mu \mathrm{m}$ ) in the road surface materials. As the silt content of a rural dirt road will vary with geographic and/or geological location, it should be measured for use in projecting emissions. For a conservative approximation, the silt content of the parent soil is often used. However, the road silt content is normally lower than in the surrounding parent soil, because the fines are continually removed by the vehicle traffic, leaving a higher percentage of coarse particles.

Other variables are important in addition to the silt content of the road surface material. For example, at industrial sites, where haul trucks and other heavy equipment are common, emissions are highly correlated with vehicle weight. On the other hand, there is far less variability in the weights of cars and pickup trucks that commonly travel publicly accessible unpaved roads throughout the country, hence carrying considerable amounts of dust and mud, especially during rainy seasons, which are directly laid down on the paved roads. For those roads, the moisture content of the road surface material may be more important in determining differences in emission levels between a hot desert environment and a cool moist location.

The following empirical expressions may be used to estimate the quantity of size-specific particulate emissions from an unpaved road in $\mathrm{Kg}$ per vehicle $\mathrm{km}$ traveled (VKT). For vehicles traveling on unpaved surfaces at industrial sites, emissions are estimated from the following equation [8]:

$$
E=k(s / 12) \wedge a(W / 3) \wedge b
$$

and, for vehicles traveling on publicly accessible roads, dominated by light duty vehicles, emissions may be estimated from the following equation:

$$
E=\frac{k\left(\frac{s}{12}\right)^{a\left(\frac{s}{30}\right)^{d}}}{\left(\frac{M}{0.5}\right)^{c}}
$$

where $k, a, b, c$ and $d$ are empirical constants, and $E=$ size-specific emission factor $(\mathrm{Kg} / \mathrm{VKT}), s=$ surface material silt content (\%), $W=$ mean vehicle weight (tons), $M=$ surface material moisture content (\%), $S=$ mean vehicle speed (kmph), $C=$ emission factor for 1980's vehicle fleet exhaust, brake wear and tire wear.

\subsection{Haphazard Driving Dust}

In most of the Iraqi territory, especially in the Western and Southern Deserts, Al-Jazira Plain, and the Mesopotamian Plain, the length of the unpaved roads is enormously increased since late seventies of the last century. This is attributed to the economic impact on the local people living there, because their yearly income was increased, and consequently, the number of their owned cars, especially pick-ups, heavy trucks and water tankers were increased. This has led to be haphazard driving by the local people in the mentioned areas, along thousands of kilometers of haphazard trucks; causing enormous disturbance to the earth surface, which in turn had increased the emission of the local dust, because the top layer was disintegrated due to wear and tear caused by the wheels of the cars. Such event was proven by the study of $[27,28]$.

\subsection{Military Actions}

During 1991 and 2003, the southern part of Iraq suffered from very large military actions. During these actions, thousands of heavy trucks and crawling military vehicles; of different types and sizes that attain more than 30 tons, have crossed the Iraqi southerly parts driving off roads. The wheeled trucks and crawlers, besides the explosion of enormous amounts of bombs and rockets of different sizes have destroyed the compacted top soil layer in large areas causing emission of dust and facilitating in development of dust and/or sand storms. Such cases are proven by the study of Dalldorf et al. and Caldwell et al. [29-31].

\section{IMPACT OF SDS ON THE ENVIRONMENT AND LIVING CONDITIONS}

The impact of the SDS on the human activities in different aspects is very harsh. It effects on health, social life, economics, transportation, and many other activities. The main aspects affected by SDS are mentioned hereinafter.

\section{Disruption to Human Activity}

In addition to the already harsh desert conditions (often accompanied by the risk of heat exhaustion and dehydration), dust and sandstorms disrupt human activity. They reduce visibility, layer on skin and clothes, infil- 
trate buildings and find their way into food and drinking water, leaving a permanent sandy feeling in your mouth. Pounding sand and dust storms also wear away textile materials, such as protective outer wear and shoes.

The storms also wreak havoc on machinery, electronics and buildings. Blowing sand and dust scour surfaces and wear away protective coverings (i.e., glass becomes frosted, wire wrap wears away and electric circuits ground out). Unfortunately, the more sophisticated an electrical system is, the more dust affects it. Dust a compact easily, solidifies with little added moisture and combines with lubricants; often resulting in clogged and/or jammed equipment and machinery. Dust and sand storms also set up electrostatic discharges that, while not typically fatal, can have negative consequences in fueling operations, computer or electrical systems.

\section{ECONOMIC IMPACT}

Dust storms cause soil loss from the dry lands, and worse: they preferentially remove organic matter and the nutrient-rich lightest particles, thereby reducing agricultural productivity [10]. Also the abrasive effect of the storm damages young crop plants [32]. Other effects that may impact the economy are: reduced visibility affecting aircraft and road transportation; reduced sunlight reaching the surface; increased cloud formation increasing the heat blanket effect, and effects to human health of breathing dust [22]. Ancient dust storm deposits known as loess are highly fertile soils, but they are also a significant source of contemporary dust storms when soil-securing vegetation is disturbed.

\section{DUSCUSSION}

Sandstorms or dust storms are caused by strong winds blowing over loose soil or sand, and picking up so much of that material that visibility is greatly reduced. The widespread abundance of loose sand in deserts makes them the most common locations for sandstorms to form. In desert regions at certain times during the year, sandstorms become more frequent because the strong heating of the air over the desert causes the lower atmosphere to become unstable. This instability mixes strong winds in the middle troposphere downward to the surface, producing stronger winds at the surface. Visibility is reduced during these storms (Figure 13) [22].

The main reasons for increasing the occurrences of SDS are the climatic changes and available water in the main two rivers, Tigris and Euphrates with their tributaries. The consequences of the drastic changes in the mean annual precipitation, and temperature and amount of available water in the rivers have increased the dry and barren lands; not only, in the whole Iraqi territory but, in the near surrounding areas.
The draught and high temperature have caused disintegration of the top soil layer and absence of the vegetation, both contribute in increasing of the SDS, almost all over the Iraqi territory, especially in the southern and western parts (Figure 14). Besides the local factors, which also contributed in disintegration of the top soil layer, such as, haphazard driving, military actions, constructions of roads, water mismanagement, and abandoning of the agricultural lands due to economic impact on the social life:, in particular the farmers.

Iraq experiences its wet season from winter through early spring, with hot, dry summers. Temperatures frequently exceed $45^{\circ} \mathrm{C}$ during late spring and summer afternoons, and will often remain above $37^{\circ} \mathrm{C}$ overnight during the summer. Dew points and humidifies are usually quite low, except at times in areas closer to the Arabian Gulf, where moisture content of the air is greater, and summer heat indices can be extremely high. These extreme changes in the climatic parameters, especially rain fall, which will be decreased by $25 \%$ and water flow will be reduced by $(20 \%-30 \%$ [11] and also the temperature (Figures 15 and 16), as compared to those which were prevailing during the last century (Table 1), had contributed in the increasing events of SDS, besides increasing the dust potential in different parts of Iraq (Figure 17).

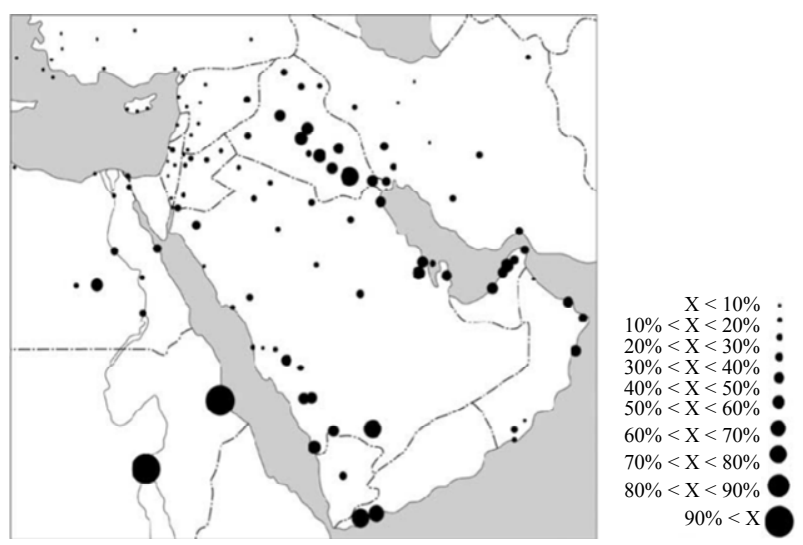

Figure 13. Spatial distribution of the maximum occurrence of visibility reduction in (\%) of the time. Circles sizes' are proportional to percentage of visibility reduction $[10,22]$.

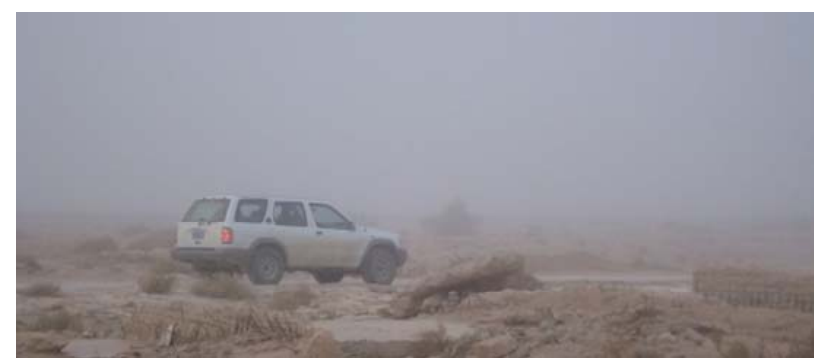

Figure 14. A dust storm in the Iraqi Southern Desert, during November, 2012. 


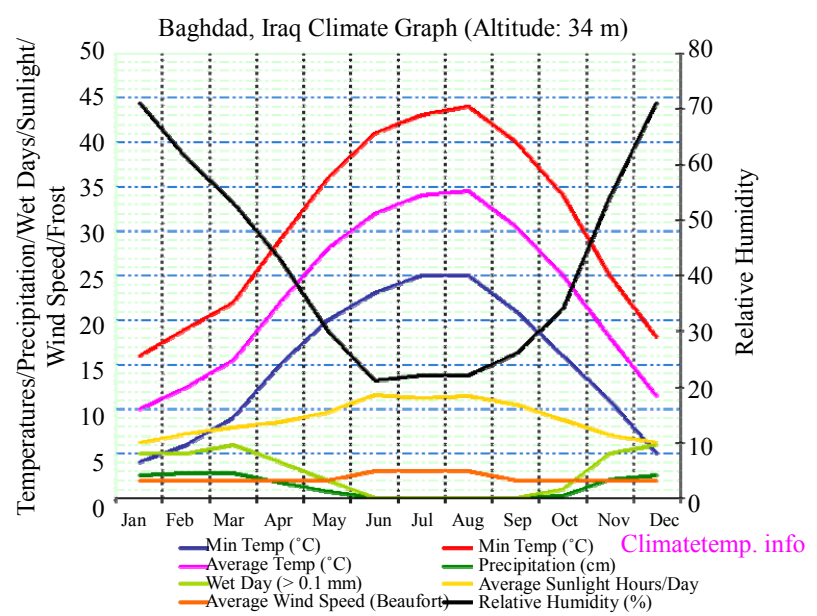

Figure 15. Climatic parameters in Baghdad, 2009 [33].

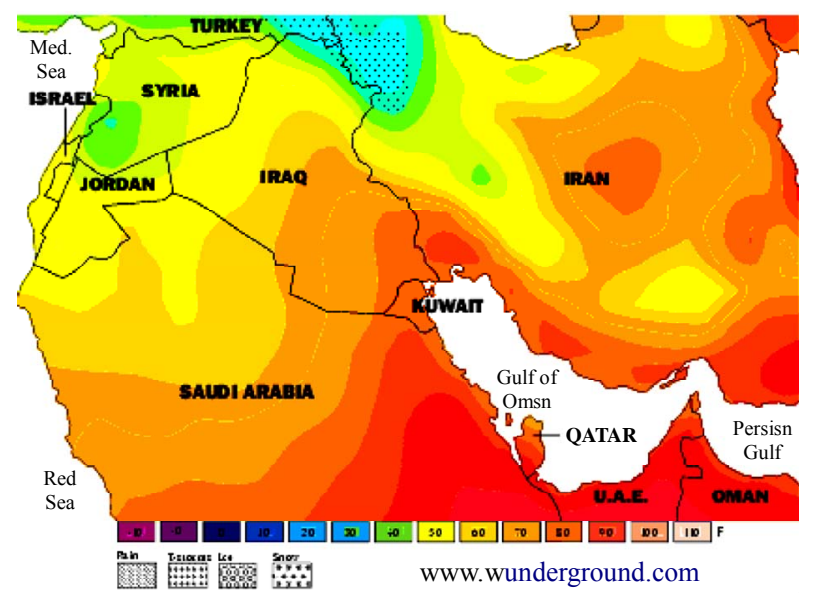

Figure 16. Temperature map of Iraq and surroundings, October, 2009 [33].

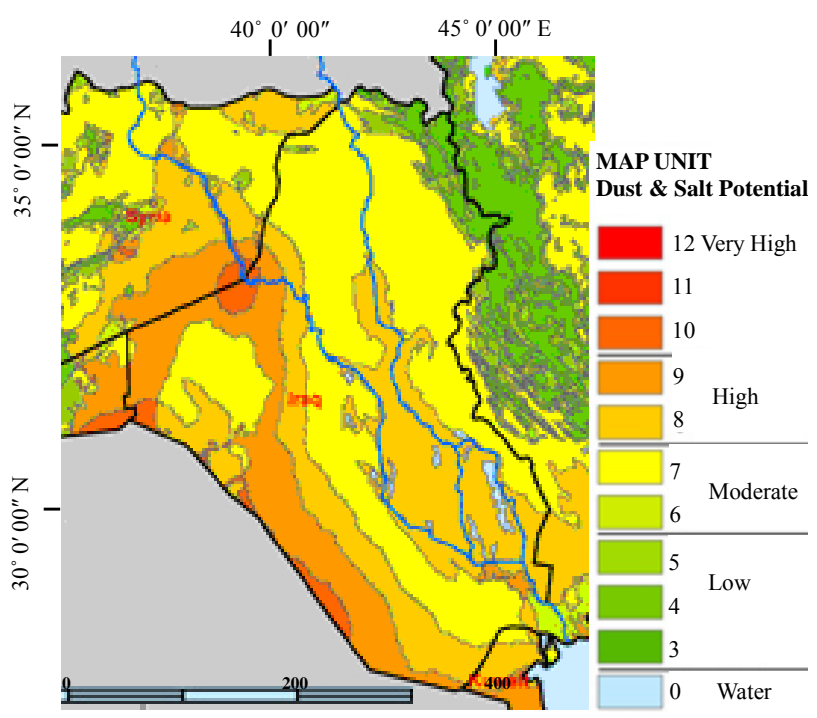

Figure 17. Dust Potential Map of Iraq [14].

To overcome this problem serious measure are to be taken by the Iraqi government. Among these measures is restoring agricultural lands and what was used to be called the green zones around the main cities. This can be achieved by using drip irrigation to save water and/or treated waste water and water harvesting technique. Prudent management of water resources can definitely save more water to combat desertification. In addition, there are number of methods to stabilize the moving dunes. Finally, restoring the marshes will definitely minimize the dust storms.

\section{CONCLUSIONS}

The main outcomes of this research are:

- The occurrences of dust and dust storms (sand storms) had enormously increased, as compared with those occurring during the last century.

- The main reason for increasing of the regional dust and dust storms is the drastic changes in annual rainfall and temperature, besides many other reasons, such as draught, mismanagement of water, abandoning of agricultural lands.

- The main reasons for increasing of local dust occurrences are haphazard driving, military actions, and construction of roads.

- The dust and dust storms have very harsh impacts on the humans' health, economic, transportation, and other social events.

To minimize the dust storms, the government should prudently manage the water resources of Iraq. Non-conventional water resources (water harvesting, Treated waste water) should be adopted and new suitable, water saving irrigation methods are to be used.

\section{ACKNOWLEDGEMENTS}

Thanks are also extended to Mr. Hayder H. Taha, for his technical support in formatting of the figures of the article.

\section{REFERENCES}

[1] Kobler, M. (2013) Dust storms of Iraq, UN Secretary General for Iraq, A ministerial meeting in Nairobi, Kenya. http://www.term123.com/dust-storms-of-iraq/\#mh32BcO B4S6cRkIG.99

[2] JAPU (Joint Analysis and Policy Unit) (2011) Sand and dust storm fact sheet. Internet data. NAOO magazine.

[3] Squires, V.R. (2007) Physics, mechanics and processes of dust and sandstorms. Adelaide University, Wikipedia, Internet data.

[4] NOAA (National Oceanic and Atmospheric Administration) (2003) Dust storms, sand storms and related NOAA activities in the Middle East.

[5] Sissakian, V.K., Abdul Ahad, I.D. and Hamid, A.T. (2011) Geological hazards in Iraq, their geographic distribution and zonation. Iraqi Bulletin of Geological Minerals, 7, 
11-28.

[6] UOF (University of Michigan) (2006) Electric sand findings. Internet data.

[7] Goldman, J. (2003) Dust storms, sand storms and related NOAA activities in the Middle East. NOAA magazine. Internet data.

[8] Brstilo, S. and Madunic, Q. (2011) Dust storms: Elemental composition, causes and environmental impacts. Windows internet explorer.

[9] UN (2013) Sand and dust storm fact sheet. http://reliefweb.int/report/iraq/sand-and-dust-storm-fact-s $\underline{\text { heet }}$

[10] Akbari, S. (2011) Dust storms, sources in the Middle East and economic model for survey it's impacts, Australian. Journal of Basic and Applied Sciences, 5, 227-233.

[11] Al-Ansari, N.A. (2013) Management of water resources in Iraq: Perspectives and Prognoses. Engineering, 5, 667684. http://dx.doi.org/10.4236/eng.2013.58080

[12] Al-Ansari, N.A. and Knutsson, S. (2011) Toward prudent management of water resources in Iraq. Journal of Advanced Science and Engineering Research, 1, 53-67.

[13] Al-Ansari, N.A., Knutsson, S. and Ali, A. (2012) Restoring the Garden of Eden, Iraq. Journal of Earth Science and Geotechnical Engineering, 2, 53-88.

[14] DTF (Integrated Desert Terrain Forecasting for Military Operations) (2013) Earth and ecosystem sciences. Internet data.

[15] Cloughton, R. (2011) A water crisis awaits Iraq. http://blogs.independent.co.uk/2011/10/26/a-water-crisisawaits-iraq/

[16] Wilson, R. (2012) Water-shortage crisis escalating in the tigris-euphrates basin, future directions international, strategic analysis paper.

http://www.futuredirections.org.au/files/FDI_Strategic_A nalysis Paper - 28 August 2012(1).pdf

[17] Kami, A. (2011) Iraq may suffer clean water crisis in 1520 years, Returs.

http://www.reuters.com/article/2011/09/21/iraq-water-idU SL5E7KL5YZ20110921

[18] Sands, P. and Latif, N. (2009) Iraq's new war is a fight for water, the national.

http://www.thenational.ae/news/world/middle-east/iraqs-n ew-war-is-a-fight-for-water

[19] IRIN (2013) IRAQ: Water shortage leads people to drink from rivers.

http://www.irinnews.org/report/70243/iraq-water-shortag e-leads-people-to-drink-from-rivers

[20] Lorenz, F.M. (2008) Strategic water for Iraq: The need for planning and action.

http://webcache.googleusercontent.com/search?q=cache: $\mathrm{NDIb}-$

nCjaE-AJ:www.wcl.american.edu/journal/ilr/24/documen ts/Lorenz.pdf $+\& \mathrm{~cd}=1 \& \mathrm{hl}=\mathrm{sv} \& \mathrm{ct}=\mathrm{clnk} \& \mathrm{gl}=\mathrm{se}$
[21] Raphael, N. (2009) Water crisis in Iraq: The growing danger of desertification, investors Iraq. http://www.investorsiraq.com/showthread.php?132306-W ater-Crisis-in-Iraq-The-Growing-Danger-of-Desertificatio $\underline{\mathrm{n}}$

[22] UNESCO-Iraq (2013) Iraq's water in the International Press.

http://www.unesco.org/new/en/iraq-office/natural-science s/water-sciences/water-in-iraq/

[23] Chulov, M. (2009) Water shortage threatens two million people in southern Iraq, The Gurdian. http://www.theguardian.com/world/2009/aug/26/water-sh ortage-threat-iraq

[24] Al-Ansari, N.A., Al-Jabbari, M.H. and McManus, J. (1978) Sediment discharge in the River Almond. Scotland, Iraqi Journal of Science, 19, 2145-2165.

[25] Al-Jabbari, M.H., Al-Ansari, N.A. and McManus, J. (1980) The effect of farming and housing upon sediment transport in a gravely river. Influence of man of the hydrological regime (Intern. Symposium), Helsinki IHS Pub. 130, 257-263.

[26] Qi, J., Al-Ansari, N. and Knutsson, S. (2013) Dust emission from unpaved roads in Luleå, Sweden. Journal of Earth Science and Geotechnical Engineering, 3, 1-13.

[27] Bacon, S.N., McDonald, E.V., Baker, S.E., Caldwell, T.G. and Stullenbarger, G. (2008) Desert terrain characterization of landforms and surface materials within vehicle test courses at US. Army Yuma Proving Ground, USA. Journal of Terramechanics, 45, 5167-5183. http://dx.doi.org/10.1016/j.jterra.2008.09.005

[28] Berli, M., Caldwell, T.G., McDonald, E.V. and Gilewitch, D.A. (2013) Modeling desert pavement deterioration due to heavy vehicle traffic. Journal of Terramechanics.

[29] Dalldorf, G.K., McDonald, E.V., Bacon, S.N. and Nikolich, G. (2008) Testing and evaluation of a synthetic polymer for dust suppression in military applications. Geological Society of America Meeting, Houston.

[30] Caldwell, T.G., McDonald, E.V. and Young, M. (2008) Soil disturbance and unsaturated hydraulic response at the US Army National Training Center, Ft. Irwin, California. Journal of Arid Environments, 67, 456-472. http://dx.doi.org/10.1016/j.jaridenv.2006.02.019

[31] Caldwell, T.G., McDonald, E.V., Bacon, S.N. and Stullenbarger, G. (2008) The performance and sustainability of vehicle dust courses for military testing. Journal of Terramechanics, 45, 213-221. http://dx.doi.org/10.1016/j.jterra.2008.10.002

[32] Wikipedia, the Free Encyclopedia (2009) Dust storms. Wikipedia, the free encyclopedia. Internet data. http://en.wikipedia.org/wiki/Dust_storm

[33] Steremberg, G. (2006) Iraq weather maps. Internet data. 